Review began 02/21/2022 Review ended 03/02/2022 Published 03/07/2022

๑) Copyright 2022

Alasker et al. This is an open access article distributed under the terms of the Creative Commons Attribution License CC-BY 4.0. which permits unrestricted use, distribution, and reproduction in any medium, provided the original author and source are credited.

\section{Characteristics and Types of Urolithiasis in the Eastern Region of Saudi Arabia: A Single-Center Retrospective Study}

Ahmed Alasker 1, 2, 3 , Saeed Bin Hamri 1, 2, 3 , Yasser A. Noureldin 1, 2, 3, 4 , Abdullah A. Alsaghyir 2, 3 Ghassan I. Alhajress 2,3

1. Urology, National Guard Hospital, Riyadh, SAU 2. College of Medicine, King Saud bin Abdulaziz University for Health Sciences, Riyadh, SAU 3. College of Medicine, King Abdullah International Medical Research Center, Riyadh, SAU 4. Urology, Benha University, Benha, EGY

Corresponding author: Abdullah A. Alsaghyir, saghyra@hotmail.com

\section{Abstract \\ Introduction}

Urolithiasis is one of the most common conditions encountered in clinical practice with the prevalence increasing globally in the last few decades. Urolithiasis has been found to be more common in areas with a hot climate, such as Saudi Arabia. The aim of this study was to determine the characteristics and the types of urolithiasis most frequently found in the Eastern Region of Saudi Arabia.

\section{Methods}

This was a single-center retrospective cohort study based on data extracted from an electronic hospital information system (BESTCare) of all patients diagnosed with urolithiasis at King Abdulaziz Hospital, a tertiary care center in Saudi Arabia's Eastern Region. From January 2013 to December 2016, all adult patients aged 18 and up who presented with urinary calculi (renal and ureter) were included in the study.

\section{Results}

A total of 235 patients were reviewed, with a mean age of 48.52 years. Renal calculi were more prevalent in males (74.5\%). Calcium oxalate was the predominant type (76\%), followed by uric acid calculi (18\%) and cystine calculi (4.8\%). A small proportion (1.2\%) was calcium phosphate calculi. The most frequently associated comorbidity was hypertension (17.9\%). The majority (78.5\%) had a stone removal through a ureteroscopy and $8.2 \%$ by percutaneous nephrolithotomy (PCNL). The mean stone size was $12.2 \pm 9.91 \mathrm{~mm}$, with a mean stone Hounsfield unit (HU) of 789.9. The mean urinary PH at stone incident was 6.77, and the mean creatinine level was $92.4 \mathrm{mmol}$.

\section{Conclusion}

This study showed that males were more affected by urolithiasis, compared to females in the Eastern Region. Furthermore, calcium oxalate was the predominant type. These findings are consistent with the literature and they highlighted the necessity for further studies in this area, to provide insight into the pathophysiology and incidence of renal calculi for improving patient care.

Categories: Urology

Keywords: urolithiasis, nephrolithiasis, stone analysis, renal stone disease, kidney calculi, renal calculi

\section{Introduction}

Renal calculi are frequent conditions encountered in urological practice, with their prevalence increasing globally in the last decades [1]. Multiple factors have been described in the literature that could influence the prevalence of renal calculi; one of which is geographic variability. The prevalence of renal calculi has been reported to be much higher in areas with a hot climate [2-5]. The risk of developing renal calculi in adults is significantly higher in the Kingdom of Saudi Arabia (20.1\%), compared to other Western countries (12\% in Canada, and $13-15 \%$ in the USA), which may be explained geographically. With the hot climate, a decrease in body fluids through perspiration and inadequate fluid intake can raise the possibility of renal calculi formation substantially. Other factors that can contribute to the formation of renal calculi are hereditary factors, dietary habits, race, gender, age, occupation, and body weight $[6,7]$.

There are many types of urinary calculi, and each has a special appearance and characteristics [8]. The most frequent type of renal calculi consists of calcium oxalate (75\%) [9]. Identification of the substance structure of calculi is a fundamental advance in the metabolic assessment, treatment, and prevention of the disease. The aim of this study was to determine the characteristics and the types of renal calculi most frequently found in the Eastern Region of Saudi Arabia. 


\section{Cureus}

\section{Materials And Methods \\ Study setting and design}

This was a single-center retrospective cohort study, based on data extracted from an electronic hospital information system (BESTCare) of patients presenting with urolithiasis at King Abdulaziz Hospital a tertiary care center in the Eastern Region of Saudi Arabia. Ethical approval was obtained from the local Institutional Review Board (SP16/143/A)

\section{Study participants and data collection}

The study included all patients aged 18 years and older, who presented with urinary calculi (renal and ureter) from January 2013 to December 2016. Data were extracted from the electronic health records. Data included demographic information in terms of age, gender, body mass index (BMI), and stone type. Data were statistically analyzed to identify the characteristics and types of renal calculi. The calculi were retrieved after lithotripsy, spontaneously, PCNL (percutaneous nephrolithotomy) or after ureteroscopy. Exclusion criteria were applied to all patients with bladder calculi and pediatric patients due to the low incidence of renal calculi in that age group.

\section{Statistical analysis}

The data were analyzed with the SPSS Statistics v. 21.0 (IBM Corp., Armonk, NY). Descriptive statistics (mean, standard deviation, frequency, and percentage) were calculated for all the variables. One-way analysis of variance (ANOVA) and a chi-square test were also performed to test the differences in selected variables. All tests with a p-value less than 0.05 were considered significant.

\section{Results}

A total of 235 patients were reviewed, with a mean age of 48.52 years. In the Eastern Region, kidney calculi were more prevalent in males (74.5\%). The majority of patients were overweight or obese and the mean BMI of $29.8 \mathrm{~kg} / \mathrm{m} 2$. The most frequently associated comorbidity was hypertension (17.9\%), followed by noninsulin-dependent diabetes mellitus (15.7\%) and insulin-dependent diabetes mellitus (3.8\%), and a small proportion (2.6\%) had dyslipidemia (Table 1$)$.

\begin{tabular}{|l|l}
\hline Study variables & N (\%) \\
\hline Age in years (mean \pm SD) & $45.9 \pm 14.0$ \\
Gender: & $175(74.5 \%)$ \\
Male & $60(25.5 \%)$ \\
Female & $29.8 \pm 6.56$ \\
BMI in kg/m2 (mean \pm SD) & \\
Comorbidities: & $42(17.9 \%)$ \\
HTN & $37(15.7 \%)$ \\
NIDDM & $09(03.8 \%)$ \\
IDDM & $06(02.6 \%)$ \\
DLP &
\end{tabular}

\section{TABLE 1: Incidence of renal stone according to age, gender, BMI, and comorbidities}

*BMI (body mass index), HTN (hypertension), NIDDM (non-insulin-dependent diabetes mellitus), IDDM (insulin-dependent diabetes mellitus), DLP (dyslipidemia).

Calcium oxalate calculi were the predominant type (76\%) of all the calculi, followed by uric acid calculi (18\%) and cystine calculi (4.8\%). A small proportion (1.2\%) was calcium phosphate calculi (Figure 1). 


\section{Cureus}

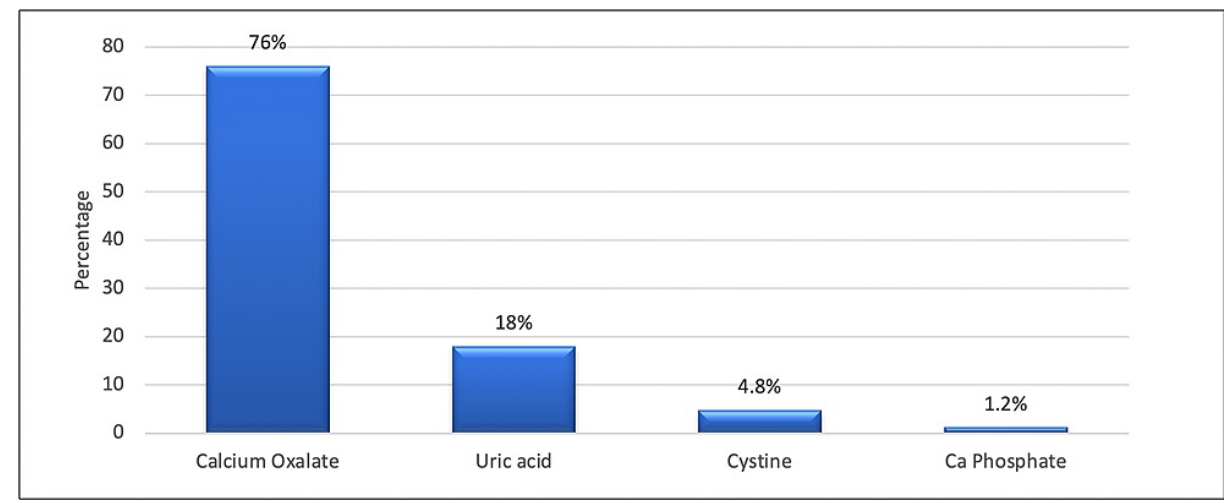

FIGURE 1: Distribution of the type of renal stone

Regarding the management, $13.4 \%$ of the patients had spontaneous stone passage with no intervention required. The majority (78.5\%) had a stone removal through a ureteroscopy and $8.2 \%$ by percutaneous nephrolithotomy. The mean stone size was $12.2 \pm 9.91 \mathrm{~mm}$, with a mean stone Hounsfield unit (HU) of 789.9. The mean urinary PH at stone incident was 6.77, and the mean creatinine level was $92.4 \mathrm{mmol}$ (Tables 2-3).

$\begin{array}{lr}\text { Variables } & \mathbf{N}(\%) \\ \text { UC } & 63(26.8 \%) \\ \text { MC } & 76(32.3 \%) \\ \text { LC } & 115(48.9 \%) \\ \text { Renal pelvis } & 51(21.7 \%) \\ \text { Upper ureter } & 30(12.8 \%) \\ \text { Mid ureter } & 06(02.6 \%) \\ \text { Lower ureter } & 09(03.8 \%) \\ \text { PH (mean } \pm \text { SD) } & 6.77 \pm 6.34 \\ \text { Stone burden in mm (mean } \pm \text { SD) } & 12.2 \pm 9.91\end{array}$

TABLE 2: Prevalence of renal stone by location

*UC (upper calyx), MC (middle calyx), LC (lower calyx). 


\section{Cureus}

\begin{tabular}{|c|c|c|c|c|c|}
\hline Factor & Ca oxalate $\mathbf{N}(\%)$ & Uric Acid N (\%) & Cystine N (\%) & Ca Phosphate N (\%) & P-value $\S$ \\
\hline Total No & 127 & 30 & 8 & 2 & \\
\hline Percentage (\%) & $76 \%$ & $18 \%$ & $4.8 \%$ & $1.2 \%$ & \\
\hline \multicolumn{6}{|l|}{ Gender } \\
\hline Male & $102(80.3 \%)$ & $27(90.0 \%)$ & 0 & $02(100 \%)$ & \multirow{2}{*}{$<0.001^{* *}$} \\
\hline Female & $25(19.7 \%)$ & $03(10.0 \%)$ & $08(100 \%)$ & 0 & \\
\hline \multicolumn{6}{|l|}{ Comorbidities } \\
\hline IDDM & $05(03.9 \%)$ & $03(10.0 \%)$ & 0 & 0 & 0.407 \\
\hline NIDDM & $19(15.0 \%)$ & $07(23.3 \%)$ & 0 & 0 & 0.446 \\
\hline HTN & $17(13.4 \%)$ & 09 (30.0\%) & 0 & 0 & 0.090 \\
\hline \multirow[t]{2}{*}{ DLP } & $03(02.4 \%)$ & $02(06.7 \%)$ & 0 & 0 & 0.446 \\
\hline & Mean \pm SD & Mean \pm SD & Mean \pm SD & Mean \pm SD & P-value $\ddagger$ \\
\hline Age in years & $48.2 \pm 13.3$ & $44.9 \pm 11.9$ & $31.9 \pm 3.04$ & $55.0 \pm 19.8$ & $0.004^{\star *}$ \\
\hline BMI in $\mathrm{kg} / \mathrm{m} 2$ & $29.8 \pm 6.06$ & $31.7 \pm 4.48$ & $31.7 \pm 5.70$ & $30.3 \pm 0$ & 0.386 \\
\hline $\mathrm{PH}$ & $6.23 \pm 0.76$ & $5.57 \pm 0.58$ & $7.50 \pm 0.89$ & $7.00 \pm 1.41$ & $<0.001^{* *}$ \\
\hline Stone size in $\mathrm{mm}$ & $10.5 \pm 7.55$ & $17.4 \pm 11.5$ & $10.2 \pm 8.15$ & $9.00 \pm 0$ & $0.002^{* *}$ \\
\hline Creatinine clearance & $91.3 \pm 26.2$ & $87.4 \pm 14.5$ & $85.5 \pm 14.8$ & -- & 0.778 \\
\hline $\mathrm{Hb}(\%)$ & $13.4 \pm 1.94$ & $13.7 \pm 2.05$ & $12.0 \pm 0.00$ & -- & 0.496 \\
\hline
\end{tabular}

\section{TABLE 3: Association between the type of renal stone among the baseline and clinical characteristics of the patients}

* IDDM (insulin-dependent diabetes mellitus), NIDDM (non-insulin-dependent diabetes mellitus), HTN (hypertension), DLP (dyslipidemia). BMI (body mass index), $\mathrm{Hb}$ (hemoglobin§ $\mathrm{P}$-value has been calculated using Fischer exact test.

$\ddagger$ P-value has been calculated using the one-way ANOVA test.

** Significant at $p<0.05$ level.

The most frequent location of the stone was in the left ureter (52.3\%) (Table 2). The uric acid calculi were significantly associated with a lower $\mathrm{pH}$ value (Table 3).

\section{Discussion}

Urolithiasis formation is widely distributed, not only in Saudi Arabia but also globally. Multiple factors contribute to the development of urolithiasis, including hereditary factors, dietary habits, dehydration, climate variables, race, sex, age, occupation, and BMI. Understanding these modifiable factors in addition to stones composition can significantly contribute to decreasing the burden of renal calculi. For instance, the pathophysiology of urolithiasis requires an understanding of the composition of renal calculi.

Prior studies explored different aspects of kidney calculi in the Central Region of Saudi Arabia. For example, Khan et al. reported an increased male: female predominance, with a ratio of 5:1 [10]. Similarly, another study in the Eastern Region by Alkhunaizi et al. indicated that males were more frequently affected than females, with a male: female ratio of 3.9:1 [11]. In the current study, the ratio of male to female was 4:1, which is consistent with Khan et al. and Alkhunaizi et al. [10,11]. In contrast, studies conducted in Canada and the United State indicated a decline in the male to female ratio for the incidence of calculi [12-15].

The current study was conducted in the Eastern Region, which is known to be the hottest area in Saudi Arabia, with a temperature reaching up to $50^{\circ} \mathrm{C}$. Dehydration, with subsequently concentrated urine, promotes an increase in urinary crystallization, supersaturation, and renal calculi formation. In this study, calcium oxalate was the most frequent type of calculi, followed by uric acid stone. This was congruent with the findings reported by Khan et al., Alkhunaizi et al., Amir et al., and Malik et al. [10,11,16,17]. 
The diversity in lifestyle in Saudi Arabia has led to a remarkable increase in the prevalence of obesity in several regions of the country. Weight abnormality has reached an epidemic level in some regions of the country where two-thirds of the Saudi citizens were overweight or obese. Obesity is usually associated with a high risk of diseases, including cardiovascular illness. Additionally, obesity is associated with an increased risk of renal calculi [18]. One study conducted in the United States concluded that obesity and weight gain were significantly associated with kidney stone formation [19]. Consistently, another study aimed to investigate the association between BMI, lipid profiles, and type of urinary calculi. Reported that the BMI was higher in stone formers, and it may be associated with different types of urinary calculi [20]. The current study revealed a positive association between BMI and renal calculi. This finding is consistent with the current literature $[11,18]$.

For years, it has been recognized that a consistently low urine $\mathrm{pH}$ is linked to uric acid nephrolithiasis, despite the fact that its significance has just lately been recognized [21]. In the present study, we also found that a low urine $\mathrm{pH}$ was associated with uric acid stone formation, supporting the current literature [21,22].

We are aware that our research has some limitations, mainly related to the retrospective nature of the study with limited sample size. In addition, some critical information from the patient medical records was missing, such as diabetes mellitus, hypertension, and 24-hour urine collection tests. Our recommendation is that multi-centric studies with a large sample size in all the Saudi Arabian regions are required.

\section{Conclusions}

The results of the current study indicated that the lifestyle of the residents based in this area, as well as the climatic nature of the region, contributed to the incidence of the stone disease; however, the small sample size and retrospective design limited this study. In addition, males are more affected by this disease, compared to females. Though the renal calculi were of different types, the calcium oxalate calculi were more prevalent in this region, compared to other types of renal calculi. These findings are consistent with the literature and they highlighted the necessity for further studies in this area, to provide insight into the pathophysiology and incidence of renal calculi for improving patient care.

\section{Additional Information}

\section{Disclosures}

Human subjects: Consent was obtained or waived by all participants in this study. King Abdullah International Medical Research Center issued approval SP16/143/A. Animal subjects: All authors have confirmed that this study did not involve animal subjects or tissue. Conflicts of interest: In compliance with the ICMJE uniform disclosure form, all authors declare the following: Payment/services info: All authors have declared that no financial support was received from any organization for the submitted work. Financial relationships: All authors have declared that they have no financial relationships at present or within the previous three years with any organizations that might have an interest in the submitted work. Other relationships: All authors have declared that there are no other relationships or activities that could appear to have influenced the submitted work.

\section{References}

1. Romero V, Akpinar H, Assimos DG: Kidney stones: a global picture of prevalence, incidence, and associated risk factors. Rev Urol. 2010, 12:e86-96.

2. Soucie JM, Thun MJ, Coates RJ, McClellan W, Austin H: Demographic and geographic variability of kidney stones in the United States. Kidney Int. 1994, 46:893-9. 10.1038/ki.1994.347

3. Boscolo-Berto R, Dal Moro F, Abate A, Arandjelovic G, Tosato F, Bassi P: Do weather conditions influence the onset of renal colic? A novel approach to analysis. Urol Int. 2008, 80:19-25. 10.1159/000111724

4. Elliott JP Jr, Gordon JO, Evans JW, Platt L: A stone season. A 10-year retrospective study of 768 surgical stone cases with respect to seasonal variation. J Urol. 1975, 114:574-7. 10.1016/s0022-5347(17)67085-X

5. Brikowski TH, Lotan Y, Pearle MS: Climate-related increase in the prevalence of urolithiasis in the United States. Proc Natl Acad Sci U S A. 2008, 105:9841-6. 10.1073/pnas.0709652105

6. John M. Eisenberg Center for Clinical Decisions and Communications Science: Lowering the chance of getting another calcium kidney stone: a review of the research for adults. Comparative Effectiveness Review Summary Guides for Consumers. Agency for Healthcare Research and Quality (US), Rockville, MD; 2013. https://www.ncbi.nlm.nih.gov/books/NBK158925/

7. Lieske JC, Rule AD, Krambeck AE, Williams JC, Bergstralh EJ, Mehta RA, Moyer TP: Stone composition as a function of age and sex. Clin J Am Soc Nephrol. 2014, 9:2141-6. 10.2215/CJN.05660614

8. da Silva SF, Silva SL, Daher EF, Silva Junior GB, Mota RM, Bruno da Silva CA: Determination of urinary stone composition based on stone morphology: a prospective study of 325 consecutive patients in an emerging country. Clin Chem Lab Med. 2009, 47:561-4. 10.1515/CCLM.2009.124

9. Aggarwal KP, Narula S, Kakkar M, Tandon C: Nephrolithiasis: molecular mechanism of renal stone formation and the critical role played by modulators. Biomed Res Int. 2013, 2013:292953. $10.1155 / 2013 / 292953$

10. Khan AS, Rai ME, Gandapur, Pervaiz A, Shah AH, Hussain AA, Siddiq M: Epidemiological risk factors and composition of urinary stones in Riyadh Saudi Arabia. J Ayub Med Coll Abbottabad. 2004, 16:56-8.

11. Alkhunaizi AM: Urinary stones in Eastern Saudi Arabia . Urol Ann. 2016, 8:6-9. 10.4103/0974-7796.164841 


\section{Cureus}

12. Scales CD Jr, Curtis LH, Norris RD, Springhart WP, Sur RL, Schulman KA, Preminger GM: Changing gender prevalence of stone disease. J Urol. 2007, 177:979-82. 10.1016/j.juro.2006.10.069

13. Lieske JC, Peña de la Vega LS, Slezak JM, Bergstralh EJ, Leibson CL, Ho KL, Gettman MT: Renal stone epidemiology in Rochester, Minnesota: an update. Kidney Int. 2006, 69:760-4. 10.1038/sj.ki.5000150

14. Strope SA, Wolf JS Jr, Hollenbeck BK: Changes in gender distribution of urinary stone disease . Urology. 2010, 75:543-6, 546.e1. 10.1016/j.urology.2009.08.007

15. Ordon M, Urbach D, Mamdani M, Saskin R, Honey RJ, Pace KT: A population based study of the changing demographics of patients undergoing definitive treatment for kidney stone disease. J Urol. 2015, 193:86974. 10.1016/j.juro.2014.09.096

16. Amir A, Matlaga BR, Ziemba JB, Sheikh S: Kidney stone composition in the Kingdom of Saudi Arabia . Clin Nephrol. 2018, 89:345-8. 10.5414/CN109313

17. Malik NA, Hussain MA: Analysis of chemical composition of urinary calculi from Northern border area of Saudi Arabia. J Pak Med Assoc. 2019, 69:885-7.

18. Siener R, Glatz S, Nicolay C, Hesse A: The role of overweight and obesity in calcium oxalate stone formation. Obes Res. 2004, 12:106-13. 10.1038/oby.2004.14

19. Taylor EN, Stampfer MJ, Curhan GC: Obesity, weight gain, and the risk of kidney stones . JAMA. 2005, 293:455-62. 10.1001/jama.293.4.455

20. Inci M, Demirtas A, Sarli B, Akinsal E, Baydilli N: Association between body mass index, lipid profiles, and types of urinary stones. Ren Fail. 2012, 34:1140-3. 10.3109/0886022X.2012.713298

21. Ngo TC, Assimos DG: Uric Acid nephrolithiasis: recent progress and future directions . Rev Urol. 2007, 9:1727.

22. Abate N, Chandalia M, Cabo-Chan AV Jr, Moe OW, Sakhaee K: The metabolic syndrome and uric acid nephrolithiasis: novel features of renal manifestation of insulin resistance. Kidney Int. 2004, 65:386-92. 10.1111/j.1523-1755.2004.00386.x 